\title{
Instrumental and affective communication with patients with limited health literacy in the palliative phase of cancer or COPD
}

Janneke Noordman ${ }^{1 *}$, Lotte Schulze ${ }^{1+}$, Ruud Roodbeen ${ }^{1,2}$, Gudule Boland ${ }^{3}$, Liesbeth M. van Vliet ${ }^{4}$, Maria van den Muijsenbergh ${ }^{3,5}$ and Sandra van Dulmen ${ }^{1,5,6}$

\begin{abstract}
Background: Patients have a 'need to know' (instrumental need) and a 'need to feel known' (affective need). During consultations with patients with limited health literacy $(\mathrm{LHL})$ in the palliative phase of their disease, both the instrumental and the affective communication skills of healthcare providers are important. The study aims to explore instrumental and affective communication between care providers and LHL patients in the palliative phase of COPD or cancer.

Methods: In 2018, consultations between LHL patients in the palliative phase of cancer or COPD and their healthcare providers were video-recorded in four hospitals in the Netherlands. As there was no observation algorithm available for this setting, several items were created to parameterize healthcare providers' instrumental communication (seven items: understanding, patient priorities, medical status, treatment options, treatment consequences, prognosis, and information about emotional distress) and affective communication (six items: hope, support, reassurance, empathy, appreciation, and emotional coping). The degree of each item was recorded for each consultation, with relevant segments of the observation selected and transcribed to support the items.

Results: Consultations between 17 care providers and 39 patients were video-recorded and analyzed. Care providers primarily used instrumental communication, most often by giving information about treatment options and assessing patients' care priorities. Care providers assessed patients' understanding of their disease less often. The patients' prognosis was not mentioned in half the consultations. Within the affective domain, the care providers did provide support for their patients; providing hope, reassurance, empathy, and appreciation and discussing emotional coping were observed less often.

(Continued on next page)
\end{abstract}

\footnotetext{
*Correspondence: j.noordman@nivel.nl

†'Janneke Noordman and Lotte Schulze contributed equally to this work.

${ }^{1}$ Nivel (Netherlands institute for health services research), PO Box 1568, 3500 BN Utrecht, Netherlands

Full list of author information is available at the end of the article
}

C C The Author(s). 2020 Open Access This article is licensed under a Creative Commons Attribution 4.0 International License, which permits use, sharing, adaptation, distribution and reproduction in any medium or format, as long as you give appropriate credit to the original author(s) and the source, provide a link to the Creative Commons licence, and indicate if changes were made. The images or other third party material in this article are included in the article's Creative Commons licence, unless indicated otherwise in a credit line to the material. If material is not included in the article's Creative Commons licence and your intended use is not permitted by statutory regulation or exceeds the permitted use, you will need to obtain permission directly from the copyright holder. To view a copy of this licence, visit http://creativecommons.org/licenses/by/4.0/ The Creative Commons Public Domain Dedication waiver (http://creativecommons.org/publicdomain/zero/1.0/) applies to the data made available in this article, unless otherwise stated in a credit line to the data. 


\begin{abstract}
(Continued from previous page)
Conclusions: Care providers used mostly instrumental communication, especially treatment information, in consultations with LHL patients in the palliative phase of cancer or COPD. Most care providers did not check if the patient understood the information, which is rather crucial, especially given patients' limited level of health literacy. Healthcare providers did provide support for patients, but other expressions of affective communication by care providers were less common. To adapt the communication to LHL patients in palliative care, care providers could be less wordy and reduce the amount of information, use 'teach-back' techniques and pay more attention to affective communication.
\end{abstract}

Keywords: Communication, Limited health literacy, Palliative care, Patients, Healthcare providers, Cancer, COPD

\section{Background}

Patients are known to have dual needs, i.e. the need to 'know and understand' (instrumental need) and the need to 'feel known and understood' (affective need), that demand instrumental and affective communication respectively [1,2]. Instrumental communication is aimed at providing information and influencing patients' understanding. Affective communication is directed towards patients' emotions and asks for empathic behaviors. A patients' need to know can be fulfilled by providing information about e.g. treatment options and prognosis, whereas a patients' need to feel known can be satisfied by e.g. providing hope or reassurance [2]. For the outcome of the medical consultation, it is important that healthcare providers (HCPs) master both instrumental and affective communication skills and can adapt their communication to the dual needs of their patients.

Communication with patients with limited health literacy (LHL) in the palliative phase of their disease places additional demands on HCPs' instrumental and affective communication skills. Almost $48 \%$ of the European population has limited health literacy [3], or $36 \%$ in the case of the Dutch population [4]. Health literacy is defined by Sørensen et al. [5] as "the knowledge, motivation and competences to access, understand, appraise, and apply health information in order to make judgments and take decisions in everyday life concerning healthcare, disease prevention and health promotion to maintain or improve quality of life throughout the course of life". LHL patients have difficulty understanding healthcare information, applying this information to their situation, and asking questions about their disease. Although these patients ask fewer questions and take less control during consultations, they actually do wish to take part in decision-making as much as other patients [6]. However, as a result of insufficient communication between LHL patients and HCPs, these patients sometimes do not receive the care and medical information they need, which reduces their health outcomes [7].

Consultations in palliative care are often complex and loaded with unspoken emotional information. The palliative phase is defined as a condition in which there are no curative options left for the disease or when there is limited life expectancy [8]. About 4.4 million people worldwide die annually of serious conditions that are preceded by a palliative phase [9]. Although it is often said that people in this phase are terminally ill, patients can actually be in this phase for a long time (in the case of chronic obstructive pulmonary disease (COPD) or cancer it may be years). In general, patients depend heavily on the support and information about their disease from their HCP. It helps them to understand what is going on better and that might help them cope with their disease and to understand the consequences for their short or long-term future.

For most patients in the palliative phase of their disease, participation in decision-making [10] and good communication are the most important elements of end-of-life care [11]. Additionally, we would like to stress the importance of understandable person-centered information, especially for LHL patients [12]. Nevertheless, many HCPs do not check sufficiently whether patients understand the information provided, do not explore what information patients need, and rarely discuss their preferences for palliative or end-of-life care $[13,14]$. A method for improving the way HCPs provide information and the patients' understanding is the 'teach-back' method: the HCP asks the patient to relate what just has been discussed. If a patient understands the information, he or she should be able to teach the information back correctly to the care provider. A recent review also found that teach-back might be useful for HCPs during consultations with LHL patients in palliative care [15].

Besides instrumental communication, affective communication also plays an important role in preparing patients for their end of life. A trustful relationship between HCP and patient is important for patients to let them feel that they can discuss everything that is on their mind during the consultations [1]. Moreover, affective communication has been found to reduce anxiety and uncertainty during bad news consultations and enhances the recall of medical information [16-18]. Additionally, affective communication is more likely to 
decrease stress-induced physiological responses in the patient, as a result of the created positive affect, social support and trust from the HCP [19]. Using emotionally loaded words and utterances, such as empathic phrases, hope and reassurance, has a major positive impact on emotional distress, which is especially relevant within palliative care $[16,18,20]$.

The present study explores the instrumental and affective communication of HCPs during consultations with LHL patients in the palliative phase of their disease. Cancer (especially lung cancer) and COPD are highly prevalent among LHL patients [21, 22]. The focus of this study is therefore on patients with cancer or COPD in the palliative phase of their disease. Insights into the communication process with this vulnerable patient group can provide input for designing communicationenhancing interventions for HCPs.

\section{Method}

\section{Aim}

This study aims to explore HCPs' instrumental and affective communication with LHL patients in the palliative phase of COPD or cancer.

\section{Study design}

An observational study was carried out in real-life clinical practice.

\section{Participants}

Patients in four participating hospitals (three teaching hospitals and one general hospital, located in different regions in the Netherlands) were included in this study if they were aged 18 or older and understood Dutch. Only participants in the palliative phase of COPD or/ and cancer were included. Additionally, they were only included if they had a lower level of education, for which the definition given by Statistics Netherlands was adopted [23] (i.e., no more than lower vocational level) and/or had LHL according to the three screening questions "Filling in hospital forms is difficult. Do you agree?", "Does someone help you fill out the doctor's forms?", and "How often do you need help for that?" [24]. Patients were excluded if they answered 'No', 'No', and 'Never' respectively to these questions. HCPs (medical specialists and nurses) in the participating hospitals were included if they had a planned consultation with a LHL patient in the palliative phase of COPD or cancer.

\section{Data collection procedure}

Consultations between LHL patients and HCPs were video-recorded between April and October 2018. Eligible patients were informed by phone a week before the planned visit to the hospital by a hospital coordinator or one of the researchers. If they expressed interest in participating, they were approached by a member of the research team in the waiting room just before seeing their HCP. If they did decide to participate, the inclusion criteria were checked and the patient signed an informed consent form before entering the consulting room, where an unmanned video camera was installed. HCPs were visible and audible on video, the patients were only audible. After the video-recorded consultation, patients received a gift voucher. Afterwards, the video recordings were stored in a secured locked room at Nivel that only the researchers had access to.

\section{Coding}

As far as we know, there was no validated observation method for observational research within the palliative setting. Observational items were therefore operationalized by three authors (JN, LS and RR) to define HCPs' instrumental and affective communication. Initially, there were seven instrumental communication items (part a) and three affective communication items (part b). These categories were based on the research protocol of a larger study called 'A basic understanding' (20172021) by five of the authors (SvD, JN, LvV, GB, and $\operatorname{MvdM}$ ) and previous literature (e.g. [2]). During the observations, the main coder (LS) added three affective communication items after discussions with two of the authors (JN and RR); empathy, appreciation (of the person or situation) and emotional coping. The resulting final items, their definitions, and examples can be found in Table 1.

While observing the video recordings, relevant segments were noted along with the start and end times, and coded with the number of the corresponding item. Initially, only the first sentence of this segment was noted down to give an impression. Later, the most relevant segments were transcribed in full to support the findings.

\section{Reliability}

The main coder (LS) observed all video-recorded consultations $(n=40)$ twice, with more than a day in between. A random selection of 10 consultations ( $25 \%$ of the total sample) were observed by a second coder (JN) to examine the reliability of the observations. All double-coded observations were discussed between these two coders to confirm that the items were based on the same concepts. One consultation was eliminated from the dataset as a result of inconsistencies between the two coders. This specific consultation was found to be relatively long and differed greatly from the others included in terms of the content (i.e., there was nothing about any medical conditions and it was more psychologically focused). In the resulting nine doubly coded consultations, 152 observations were found in total (by at least one of the two 
Table 1 Items for coding HCPs' instrumental communication (a) and affective communication (b) during consultations with LHL patients in the palliative phase of cancer or COPD

\begin{tabular}{|c|c|c|}
\hline a. Instrumental communication & Definition & Examples (as defined a priori) \\
\hline $\begin{array}{l}\text { 1. Assessment of patients' } \\
\text { understanding of their disease }\end{array}$ & $\begin{array}{l}\text { The HCP asks questions about the provided information, to see if the } \\
\text { patient understood. Including the teach-back method. }\end{array}$ & $\begin{array}{l}\text { "Do you understand what I just said?" } \\
\text { "Could you maybe explain ..." }\end{array}$ \\
\hline 2. Assessment of patient priorities & $\begin{array}{l}\text { The HCP assesses and/or mentions the priorities and preferences of } \\
\text { the patient. }\end{array}$ & $\begin{array}{l}\text { "I'd like to know what's important for } \\
\text { you." } \\
\text { "I can imagine that you'd like to continue } \\
\text { your swimming, wouldn't you?" }\end{array}$ \\
\hline $\begin{array}{l}\text { 3. Provision of information about } \\
\text { current medical status }\end{array}$ & The HCP gives medical information and explains it to the patient. & $\begin{array}{l}\text { "As we can see on the CT scan ..." } \\
\text { "Comparing these results with the last } \\
\text { time..." }\end{array}$ \\
\hline $\begin{array}{l}\text { 4. Discussion of information } \\
\text { about treatment options }\end{array}$ & $\begin{array}{l}\text { The HCP suggests one or more possible treatment options and } \\
\text { explains them. }\end{array}$ & $\begin{array}{l}\text { "Starting chemotherapy would be one } \\
\text { possibility." } \\
\text { "I'Il explain the treatment options to you." }\end{array}$ \\
\hline $\begin{array}{l}\text { 5. Discussion of information } \\
\text { about treatment consequences }\end{array}$ & $\begin{array}{l}\text { The HCP discusses the consequences of a treatment, e.g. the side } \\
\text { effects. }\end{array}$ & $\begin{array}{l}\text { "It's possible that you will feel nauseous } \\
\text { after taking these medicines." }\end{array}$ \\
\hline 6. Discussion of prognosis & $\begin{array}{l}\text { The HCP discusses the expectations of the course of the disease } \\
\text { within a certain time frame. }\end{array}$ & $\begin{array}{l}\text { "The illness will probably become more } \\
\text { active over time." } \\
\text { "These medicines will have an effect } \\
\text { within three weeks." }\end{array}$ \\
\hline $\begin{array}{l}\text { 7. Giving information about } \\
\text { emotional distress }\end{array}$ & The HCP gives information about the effect on emotions. & $\begin{array}{l}\text { "It's possible that you will feel lonely." } \\
\text { "Your situation may also influence your } \\
\text { mental wellness." }\end{array}$ \\
\hline b. Affective communication & Definition & Example \\
\hline 1. Hope & The HCP sheds highlights the positive aspects of the situation. & "That looks very good!" \\
\hline 2. Support & The HCP emphasizes that the patient is not alone. & "We'll do this together." \\
\hline 3. Reassurance & The HCP tries to make the patient feel at ease. & "Don't worry about that." \\
\hline 4. Empathy & The HCP shows that he or she understands the patients' situation. & $\begin{array}{l}\text { "I can imagine that you are afraid, going } \\
\text { through all this." }\end{array}$ \\
\hline 5. Appreciation & $\begin{array}{l}\text { The HCP shows that he or she appreciates the patient as a person/ } \\
\text { being. }\end{array}$ & $\begin{array}{l}\text { "I really do respect the way you're } \\
\text { keeping going." }\end{array}$ \\
\hline 6. Emotional coping & The HCP asks how the patient deals with their emotional distress. & $\begin{array}{l}\text { "And what's your response to this } \\
\text { unpleasant situation?" }\end{array}$ \\
\hline
\end{tabular}

coders or both). The observations of the second coder matched those of the main coder in $86 \%$ of cases, whereas the observations of the main coder matched those of the second coder in 95\% of cases; both percentages indicate good agreement between observers.

\section{Analysis}

The frequencies for each consultation of all the coded items were analyzed using STATA-14. Background characteristics of patients and HCPs were added for each consultation: the function and gender of the HCPs; the gender, age, and educational level of patients; the answers to the three LHL questions; and whether or not there was another person present during the consultation to assist the patient. Finally, the duration of the consultation, the type of consultation (new, control or composite) and the patients' disease were recorded. Descriptive analyses were performed on the abovementioned variables in STATA-14. In order to substantiate the frequencies, the main coder looked through the various transcribed observations and picked out the most significant (initial sentences of the) quotes. This resulted in around three quotes per item that were then transcribed verbatim, after removal of any personal identifiers. After discussion with the second coder, some quotes were eliminated because they were vague without the context of the whole consultation or because of overlap with other quotes. The remaining quotes were used to substantiate the coded items.

\section{Results}

\section{Participants}

Seventeen HCPs participated in the study, of whom ten were women and seven were men. The HCPs were physicians $(n=10)$, physicians in training $(n=1)$ or nurses $(n=6)$. An average of two consultations were recorded per HCP (SD 1.21, range 1-5). In most of the consultations, there was one HCP present, except for two consultations with two HCPs involved. During six 
consultations, a physician in training attended the consultation but was not involved in the conversations.

A total of 39 patients were included, 21 men and 19 women (52.5 and $47.5 \%$, respectively). In 33 consultations, the patient was accompanied by a companion ( 20 by their partner, 9 by their son or daughter and 4 by someone else). Of the included patients, 31 had a low level of education, 6 had a medium level and 2 a high level; in one patient, the educational level was unknown. Seven patients who said they were not LHL were nevertheless included based on the opinion of their HCP who considered them to have low health literacy or to be vulnerable in communication. Five of these had a lower level of education and two had a medium level. Thirteen patients were diagnosed with COPD, 26 were diagnosed with cancer and one patient with an anomaly of the lung.

\section{Consultations}

The consultations had an average duration of $22.53 \mathrm{~min}$ ( $\mathrm{SD}=13.13$; range 5.57-69.58). Three consultations were first (new) consultations, 29 were checkup visits and 8 were composites (i.e., a follow-up consultation in which the patient presented new problems or symptoms).

\section{Instrumental communication by HCPs}

In general, HCPs primarily communicated instrumentally, spreading this across various items. Interestingly, the duration of the instrumental communication fragments was longer than the duration of the affective communication fragments during the consultations. The total number of each item is shown in more detail in Table 2. Additionally, a quote is given as an example of each item. More quotes related to the items can be found in Additional file, Annex A.

\section{Assessment of the patients' understanding of their disease} In the majority of consultations $(n=25)$, patients' understanding of their diseases was not assessed by the HCP.
In most of the other consultations, this understanding was assessed once $(n=10)$. In total, this item was mentioned least often of all the observed instrumental communication aspects (21 times).

Checking if the patient understood the information let the HCP verify whether they had explained the information clearly to the patient and, if needed, they could then re-explain and check again. This could be attempted by questions such as 'what did we discuss previously?' or more elaborate by using the teach-back method mentioned earlier. In the quote below, the HCP asked the patient to summarize what they remembered about the last conversation. Additionally, the $\mathrm{HCP}$ explained the reason for asking.

"Maybe it would be most convenient for me to go back to Friday's conversation, if you would please summarize for me what I explained then, as we discussed a lot of material already then. Lots of information at once. So maybe it is nice for me to (...) know what has stuck (...). Then I know where to start, because oxygen is all linked to that. What can you remember about that?" (Z1L05).

\section{Assessment of the patients' priorities}

In most consultations $(n=10)$, the HCP mentioned the patients' priorities twice. In eight consultations it was mentioned once, while in seven it was not mentioned at all.

HCPs assessed patients' priorities for their treatment options and took into account the wishes and circumstances of the patient. The following quote is an example of a HCP who tried to involve the patient in decisionmaking. In doing so, the HCP provides space and time for the patient to think about their own priorities.

"In the end, you decide with us, don't you? Because it's your body, so really think about it, what you want and what you don't." (Z1LO3).

Table 2 Instrumental communication by HCPs: items discussed and number of times discussed

\begin{tabular}{|c|c|c|c|c|c|c|}
\hline $\begin{array}{l}\text { Instrumental } \\
\text { communication } \\
\text { items }\end{array}$ & $\begin{array}{l}\text { Not } \\
\text { discussed/ } \\
\text { provided }(n)\end{array}$ & $\begin{array}{l}\text { Discussed/ } \\
\operatorname{provided}(n)\end{array}$ & $\begin{array}{l}\text { Mentioned once } \\
\text { per consultation }\end{array}$ & $\begin{array}{l}\text { Mentioned two } \\
\text { times per } \\
\text { consultation }\end{array}$ & $\begin{array}{l}\text { Mentioned more } \\
\text { times per } \\
\text { consultation }\end{array}$ & $\begin{array}{l}\text { Total number of times } \\
\text { subject is discussed }\end{array}$ \\
\hline 1. Understanding & 25 & 14 & 10 & 2 & 2 & 21 \\
\hline 2. Priorities & 7 & 32 & 8 & 10 & 14 & 87 \\
\hline 3. Medical status & 1 & 38 & 8 & 7 & 23 & 110 \\
\hline $\begin{array}{l}\text { 4. Treatment } \\
\text { options }\end{array}$ & 13 & 26 & 7 & 6 & 13 & 84 \\
\hline $\begin{array}{l}\text { 5. Treatment } \\
\text { consequences }\end{array}$ & 12 & 27 & 16 & 9 & 2 & 43 \\
\hline 6. Prognosis & 18 & 21 & 7 & 8 & 6 & 48 \\
\hline $\begin{array}{l}\text { 7. Giving information } \\
\text { about emotions }\end{array}$ & 28 & 11 & 10 & 1 & 0 & 12 \\
\hline
\end{tabular}


Some HCPs also took the patients' personal life into account. For instance, they asked about patients' daily affairs (like work or hobbies) to make sure that certain decisions fitted in their daily life.

"Because you have a job, don't you? How many days do you work?” (Z3LO3).

\section{Provision of information about current medical status}

In most consultations $(n=11)$, information about the patients' current medical status was provided three times by the HCP. This item of instrumental communication was therefore mentioned the most often in all consultations (110 times). In one consultation, this information was not provided. The reason seemed to be the limited time of the consultation. Moreover, the purpose of that particular consultation was to check if certain complaints were present, which was not the case.

Almost all HCPs provided information about the medical status and development of the patients' disease. Most HCPs presented this information to the patient using their computer screen at the beginning of the consultation. During this item the HCPs spoke most of the time; the patients sometimes asked questions in between or afterwards. In the following example, the HCP explained the results of a CT scan to the patient.

HCP: "What you see in the blood is that the CEA, the substance that makes the cancer, is rising. Well, it's 8.9 now and last time was 6.6 and, it's come up from 2.4 around this time last year. And we did that CT scan, which shows that the cancer is still growing."

Patient: "OK. Everything?"

HCP: "All the spots in the lungs have gotten a little bigger. There is a larger abnormality in the lungs too. It was about two centimeters; it has now become three centimeters. In particular the largest tumor, which is the most obvious, has also grown. And all those other small spots that were only a millimeter in size, well, they've also grown a few millimeters. But especially the tumor that went from two to three." (Z3O04).

Sometimes the HCP repeated or summarized what had been discussed in previous consultations, especially when the patient could not remember (or only partially) or could not teach back the information provided (see item 1). See for example the quote below from a HCP summarizing the disease history of the patient and what was discussed during a previous consultation.

"To summarize: she was admitted with pneumonia. We have treated it, but we also know that she has
COPD, of course. So you've been smoking through the years and your lungs have worn out, as it were. Lung damage has occurred that can no longer be made better. And that means that at the moment there is an infection in which the respiratory tract is continuously too irritated - it's a chronic condition. And if anything comes on top of that, the whole house of cards collapses. That's accompanied by more mucus, stuffiness, things like that. What I explained last time is that there is a difference between the way the lungs function in a healthy person and in someone with COPD." (Z1LO5).

\section{Discussion of information about treatment options}

Information about treatment options was not discussed in 13 consultations. We do not however know which treatment options were still available for patients. When treatment options were discussed, they were mentioned once in most consultations $(n=7)$.

In a number of consultations, HCPs discussed the options for starting a treatment to minimize certain complaints. This could be a medically invasive option such as surgery or chemotherapy, but it could also be additional to the current treatment, such as psychological help or physiotherapy. In the example below, the HCP listed different treatment options that the patient could take into consideration for dealing with their somatic and psychological complaints.

"What you can consider, of course, is pulmonary rehabilitation. That should be possible, and it's also an option in itself. You can do that at home in primary healthcare, as they say. For example, twice a week with a physiotherapy trainer. You can do it here in the hospital, three times a week; that's a somewhat heavier program. And then not only physiotherapy, but also dietetics, possibly the psychologist, social work if necessary, the lung nurse, who is continuously present. Occupational therapy if necessary, to see if you still need medical aids. You can do that. Or you go to what we call tertiary rehabilitation, but then you should think of the rehabilitation center. I think you could get started with that too. But you have to be able and willing to do that. But we can talk about that next time; maybe we should talk about that depending on those results." (Z3LO2).

\section{Discussion of information about treatment consequences}

In most of the consultations $(n=27)$, the information about treatment consequences was given once $(n=16)$, or twice $(n=9)$. In 12 consultations, no treatment consequences were given by the HCP. However, it is not known in how many consultations talking about a 
treatment option was possible. From another observation within the same study (Roodbeen et al., submitted) it was concluded that in 36 of all 40 consultations a treatment decision was made.

When information about available treatments was provided to a patient, the HCP could outline the consequences of this specific treatment by addressing the advantages and disadvantages. In the quote below, the HCP discussed one advantage and one disadvantage of inserting a stent, which helps the patients to make an informed decision about the treatment.

"The advantage of a stent is that food can pass very quickly, because it just makes room right away. The downside of a stent is that it doesn't do anything against malignant cells, does it? It only makes space. And if you wait over time, the active disease, the malignant disease, can start to grow again. So that also reinforces ... (...) Well, those are disadvantages, aren't they?" (Z2R06).

The treatment consequences also included potential reasons for not choosing a certain treatment, as in the following quote. This quote is also an example of one of the few times that HCPs talked with the companion instead of the patient.

"I'm a bit afraid of that if I give that for a long time, that she could get complaints." (Z1L05).

\section{Discussion of prognosis}

The patients' prognosis was not discussed in nearly half of the consultations $(n=18)$. When the prognosis was discussed, it was often discussed twice $(n=8)$. However, we do not know whether the HCPs had enough information to make a correct prognosis for all patients in every consultation. Even when enough information is available, it is hard for HCPs to make a correct prognosis. Additionally, we do not know whether patients were already aware of their prognosis or if they wanted to discuss it during the recorded consultation.

HCPs provided prognostic information about how the patients' disease was expected to develop. For instance, the chance of successful treatment or how a medicine works was discussed. Sometimes the HCPs mentioned other patients' experiences with the same treatment. In the example below, the HCP drew a picture of how the patients' disease might develop.

"However, the disease is slowly getting more active. And one of the things that you see happening most often is that people often get tired. People get ... when you have cancer, you hear very often that people get tired. Your battery ... your battery does not recharge properly, it can no longer charge properly. Put it this way: everyone has a battery - that's how I see it as a doctor, right? And well, and then people rest more. Suppose you suddenly get anemic - you can get that theoretically. Well, if that's bad and you're still fairly mobile, then you get given some blood. To give an example." (Z3L05).

\section{Giving information about emotional distress}

Information about possible emotional distress was given in less than half of the consultations $(n=11)$. When discussed, it came up once per consultation, with one exception when it was discussed twice.

Besides the medical and treatment information, HCPs also provided information about the emotions (mostly negative) that could arise as a result of the patients' disease. Contrary to affective communication about emotional coping, this item demonstrates the information that was given by the HCP about the emotions that the patient could possibly experience.

"Because they also pay attention to the psychological side of things, for example. There are, of course, quite a lot of people who, well, if you have a chronic illness, you sometimes get down. Or get anxious. That isn't crazy at all, of course." (Z1LO8).

Additionally, some HCPs acknowledged the emotions shared by the patient and mentioned that their emotional reaction was normal.

"Those are all things that will be very difficult now."(Z1LO7).

\section{Affective communication}

The affective communication by HCPs differed, as can be seen in Table 3. Most HCPs supported for their patients, but other affective communication by HCPs was less common. More quotes on affective communication can be found in Additional file, Annex B.

\section{Hope}

In most of the consultations $(n=22)$, hope was not mentioned by HCPs. When hope was mentioned, it was most often mentioned once $(n=12)$.

HCPs try to give some positive possibilities for the near or longer-term future to the patient. They say for instance that they hope the medicine will work, or that the treatment will not produce too many side effects. The following quote illustrates hope introduced by the HCP.

"Well, we're going to try to stop it. We're hoping to make it smaller and there's a very good chance of 
Table 3 Affective communication by HCPs: items discussed and number of times discussed

\begin{tabular}{|c|c|c|c|c|c|c|}
\hline $\begin{array}{l}\text { Items of affective } \\
\text { communication }\end{array}$ & $\begin{array}{l}\text { Not discussed/ } \\
\text { provided }(n)\end{array}$ & $\begin{array}{l}\text { Discussed/ } \\
\operatorname{provided}(n)\end{array}$ & $\begin{array}{l}\text { Mentioned once } \\
\text { per consultation }\end{array}$ & $\begin{array}{l}\text { Mentioned two } \\
\text { times per } \\
\text { consultation }\end{array}$ & $\begin{array}{l}\text { Mentioned more } \\
\text { times per } \\
\text { consultation }\end{array}$ & $\begin{array}{l}\text { Total number of times } \\
\text { subject is discussed }\end{array}$ \\
\hline Hope & 22 & 17 & 12 & 4 & 1 & 23 \\
\hline Support & 8 & 31 & 12 & 7 & 12 & 77 \\
\hline Reassurance & 23 & 16 & 7 & 5 & 4 & 29 \\
\hline Empathy & 21 & 18 & 9 & 5 & 4 & 38 \\
\hline Appreciation & 30 & 9 & 8 & 1 & 0 & 10 \\
\hline Emotional coping & 25 & 14 & 9 & 3 & 2 & 21 \\
\hline
\end{tabular}

that. And then we hope it stays quiet for a long time." (Z3O04).

Hope was also provided without mentioning the word itself, like in the following quote.

"We assume that we're done. We're assuming that you are now clean." (Z2LO6).

\section{Support}

Overall, support was mentioned most often of all the affective communication items (78 times in total). HCPs mentioned support once in most of the consultations $(n=12)$, with a maximum of seven times in one consultation. In eight consultations, no support was offered.

Offering support lets the HCP emphasize that the patient is not left on his or her own, or that the HCP (and the whole medical team) will support the patient as much as possible. The word 'we' is important in this case because it focuses on the collaboration between HCP and patient. For this item to be coded, the word 'we' had to suggest support from the care provider and not just a generalized use (e.g., "Did we have a good week?"). This support could help build a relationship in which the patient feels more at ease and supported in their illness, as is illustrated in the following quote.

"We are all here to keep you alive for as long as possible on the one hand, and to keep you alive as best as possible on the other." (Z2LO8).

\section{Reassurance}

Most of the consultations $(n=23)$ did not contain any reassurance by the $\mathrm{HCP}$, but 16 did, mostly once in each consultation. HCPs tried to overcome unrealistic (negative) thoughts or feelings of patients by reassuring them, e.g. by correcting negative assumptions about the treatment or medication. Whereas hope concentrates on positive feelings for the future, reassurance focuses on reforming the negative feelings into positive feelings in the present, as shown in the following quote.
"We don't want to irradiate you so often, you know." (Z2R07).

In the quote below the HCP tried to ease the patients' concerns and fears.

"So that's it again: every cloud has a silver lining, so to speak." (Z2R06).

\section{Empathy}

HCPs did not show empathy verbally to patients in more than half of the consultations $(n=21)$. When present, it was most often given once $(n=9)$ or twice $(n=5)$.

Empathy lets the HCPs show that they acknowledge the patients' psychological or emotional feelings or practical experiences, as is illustrated in the following quote.

"Yes, I can imagine: not conducive to sleep at all."

(Z4A04).

\section{Appreciation}

In these consultations, most HCPs did not verbally express appreciation of the patient; it was not mentioned in 30 consultations. When mentioned, it was done mostly once $(n=8)$ per consultation. Overall, this item was mentioned least (10 times) out of all the affective communication items.

Examples of appreciative comments were confirmation that the patient was acting bravely or respect for the patients' hard work. An example of an appreciative remark for the patient is shown below.

"I always admire you, because you always try to do as little as possible." (Z4A04).

Appreciation could also be shown about the medical situation rather than the patient, as in the following example:

"I am actually also satisfied. I am glad that it has recovered so much." (Z1L10 \& 11). 


\section{Emotional coping}

Emotional coping was not discussed in more than half of the consultations $(n=25)$. When discussed, this was mostly done once $(n=9)$.

The HCP could ask about the way the patient deals with all the emotional distress, as it is shown in the following quote.

\section{"Well, that's very difficult because ... well, what do you do at such a moment?" (Z3LO2).}

Some HCPs explicitly asked how the patient or family was feeling. They wondered how the patient was dealing with emotional or other difficulties, as for example in the quote below where a HCP spoke to a patient whose wife has passed away recently.

"How are you getting on now that you're on your own?” (Z4A06).

It is worth noting the fact that some HCPs also addressed the emotional coping by the patients' companion. This happened once in two consultations.

\section{Discussion}

This study aimed to explore the instrumental and affective communication between HCPs and LHL patients in the palliative phase of COPD or cancer. Our study showed that HCPs provided mostly instrumental communication to their LHL patients. Information about treatment options was mentioned most often, in almost all consultations. Moreover, our results show that most HCPs did not check patients' understanding and did not use the teach-back method.

Zooming in on the specific quotes about instrumental communication (especially concerning information provision about the patients' medical status), we believe the HCPs often provided too much information, using difficult words and lengthy sentences that were not adapted to LHL patients. This 'wordiness' (using more and more difficult words than actually needed) could have resulted in information being provided unclearly to LHL patients. Although we did not ask about the needs and understanding of the provided information of patients in this specific study, we do know that LHL patients can on average remember a maximum of three subjects per consultation [25]. Additionally, previous research has shown that cancer patients as a whole (not only LHL patients) forget more than half the information provided (about diagnosis, prognosis, and treatment), independently of their age [26].

In contrast, we were pleased to find that HCPs assessed patients' priorities in the majority of the consultations. This indicates that HCPs take account of the wishes and circumstances of the patient. These findings differ from previous research, which found that HCPs do not always check the patients' priorities or what is important for their patients [13, 14]. As mentioned before, the majority of patients in the palliative phase do want to participate in treatment decisions [10] and list good communication as one of the most important elements of end-of-life care [11]. Recent research has shown that LHL patients also want to participate in decision-making, but need the support to do so [12].

Another finding is that patients' prognoses were not mentioned during almost half of the consultations. Previous research has shown that many cancer patients have unresolved questions about their prognosis and do not understand the prognosis provided [27]. However, not all patients want to discuss their prognosis in every consultation [28]. Additionally, many oncologists avoid discussing the prognosis or provide rather optimistic results [29]. Giving a prognosis for COPD patients is more difficult than for cancer patients as a result of the lengthy course of COPD. This also hinders communication about the end of life for these patients [30] and probably especially for LHL patients as they need clear information (e.g. short sentences, no jargon) in the present tense [31]. Another possible explanation for our findings could be that the prognosis has already been discussed with the patient in an earlier consultation, or will be discussed in a subsequent visit. As mentioned before, it is important that HCPs ask patients (not only LHL patients) about their wishes regarding prognosis information, and adapt their instrumental and affective communication accordingly.

With respect to affective communication, most of the HCPs did provide supportive words to their patients. Other affective communication, such as hope, reassurance, empathy, appreciation, or discussing emotional coping, were observed less often. Previous research among COPD patients has shown that patients want to receive emotional support and discuss end-of-life care with their physicians [30]. According to a scoping review [32], the emotional engagement of a HCP could empower, enable, and encourage the patient to take control of their disease. Focusing specifically on LHL patients, a survey study by Chu and Tseng [33] suggested that HCPs' empathy could help LHL patients understand preoperative information better. The authors therefore claim that improving empathic communication should get priority, especially for LHL patients. Although it is sometimes difficult to find the balance between providing hope and being realistic, reassurance provided by oncologists and pulmonologists could decrease patients' uncertainty and anxiety and could also increase their self-efficacy and satisfaction [34]. According to Olsman et al. [35], there are three perspectives of hope that 
could improve HCPs' communication: the realistic, the functional and the narrative perspectives. Hope could not only be given about the outcomes of the illness itself, but also about side effects or someone's wellbeing. Additionally, appreciation of the patient and their behavior and understanding their identity and fears are found to be very important factors in supporting patients [36].

Furthermore, we found that instrumental communication fragments were longer than affective communication fragments. This suggests that instrumental communication takes up the larger part of the consultation while affective communication aspects receive only seconds or perhaps minutes. This does not necessarily have to be a problem. For example, the study by Fogarty and colleagues [37] showed that $40 \mathrm{~s}$ of compassion could have a positive effect on the anxiety of female patients with breast cancer. This finding suggests that affective communication does not have to take up a lot of time within the consultation. However, these patients were not screened for health literacy. So the question arises of whether this is different in consultations with LHL patients. More research is needed to understand the optimal duration of affective communication and these time differences and what they mean.

\section{Strengths and limitations}

To our knowledge, this is the first study to explore the instrumental and affective communication of HCPs with LHL patients in the palliative phase of cancer or COPD by analyzing real-life consultations. We have created several items that we believe collect relevant data about the communication skills of HCPs in this setting and these were coded reliably.

Some limitations are worth mentioning. Firstly, although the coded items provided relevant data about the communication and these items were coded reliably, we did not validate the items. In addition, the division between instrumental and affective communication is somewhat artificial and not always evident, i.e. these are theoretical concepts that can overlap in practice.

Secondly, we focused on positive expressions by HCPs. We did not code a lack of expressions, e.g. not showing empathy or not discussing treatment options (so called 'missed opportunities'). Moreover, as we only coded verbal affective communication, the HCPs may possibly have used affective expressions non-verbally. Their reactions also depend on the non-verbal expressions of their patients, who were not visible.

Thirdly, the HCPs were aware that our study was focusing on their communication with LHL patients. This could have influenced their behavior. They were, however, unaware of the specific focus on instrumental and affective communication.

Fourthly, there was sometimes disagreement between the patients' and HCPs' assessments of the patients' level of health literacy. This might be related to the fact that patients with limited health literacy often hide the fact that they do not understand health information because they are ashamed [12,38]. In addition, due to time constraints or patients' emotional overload, eight patients were not asked the three screening questions. These patients were included based on the opinion of the HCP, which could have biased our population.

Fifthly, the coded video-recorded consultations were snapshots of daily practice. It is possible that topics that were not discussed in the recorded consultation had already been discussed in a previous consultation or would be discussed in a future one.

Because of the small sample size, it was not possible to look at differences between male and female patients, between the individual HCPs, between first and follow-up consultations, or between patients with cancer or COPD. However, these differences could have influenced the instrumental and affective communication of the HCPs.

Lastly, the items identified could be based on the coders' personal and cultural values and backgrounds, especially for affective communication. For instance, previous research has shown that oncologists think the definitions of reassurance and hope overlap to some extent [39].

\section{Recommendations for research and practice}

To adapt the communication to LHL patients in palliative care, HCPs could reduce their 'wordiness' and simplify their language (i.e., use short sentences in the present tense) and the amount of information (i.e., discuss a maximum of three subjects [25]), use the teach-back technique and pay attention to affective communication, especially as previous research found that empathy could help patients to understand the information better [33].

Future research could focus on the appropriate amount and quality of information provision and affective communication according to both LHL patients in palliative care and HCPs. The understanding and recall of information by LHL patients of this current study will be addressed as part of the larger study ('A basic understanding').

\section{Conclusion}

HCPs provided mostly instrumental communication, especially treatment information, in consultations with LHL patients in the palliative phase of cancer or COPD. Most HCPs did not check if the patient understood the information, which is rather crucial, especially given patients' limited level of health literacy. HCPs did support the patients but other forms of affective communication by HCPs were less common. To adapt the communication to LHL patients in palliative care, HCPs could reduce their wordiness and simplify their language, reduce the amount of information, use the teach-back technique and pay attention to affective communication. 


\section{Supplementary information}

Supplementary information accompanies this paper at https://doi.org/10. 1186/s12904-020-00658-2.

\section{Additional file 1.}

\section{Abbreviations}

HCP: Healthcare provider; LHL: Limited health literacy

\section{Acknowledgements}

We would like to thank the participating hospitals, healthcare providers and patients for their cooperation. We also thank Wietske van der Hoeven for collecting the video-recordings and Tessera Translations (Mike Wilkinson) for the language editing.

\section{Authors' contributions}

JN and LS contributed equally. JN participated in the design of the study, carried out the reliability analysis and the interpretation of the data and wrote the first draft of the paper. LS carried out the coding and analysis, the modeling of the data and wrote the first draft of the paper. RR collected the data, helped interpret the data and helped draft the paper. GB, LVV and MvM participated in the design of the study and helped draft the paper. SvD participated in the design of the study, the interpretation of the data and helped draft the paper. All authors read and approved the final manuscript.

\section{Funding}

This study was funded by a grant from the Netherlands Organisation for Health Research and Development, Palliative Care Program (ZonMw, Palliantie: 844001403).

LVV is supported by a young investigator grant from the Dutch Cancer Society (10392).

The funders had no role in the design of the study and the decision to submit this manuscript.

\section{Availability of data and materials}

The datasets used and/or analyzed during the current study are available from the corresponding author on reasonable request.

\section{Ethics approval and consent to participate}

The Arnhem-Nijmegen Medical Research Ethics Committee (2017-3623) ruled that no formal ethics approval was required in this particular case. The committee decided that the study did not fall within the remit of the Medical Research Involving Human Subjects Act (Dutch: WMO) and had no objections to this study taking place.

All participants were informed (verbally and in writing) about the study and signed an informed consent form. Participants' anonymity was assured and they could withdraw from the study at any time.

\section{Consent for publication}

Not applicable.

\section{Competing interests}

The authors declare that they have no competing interests.

\section{Author details}

${ }^{1}$ Nivel (Netherlands institute for health services research), PO Box 1568, 3500 BN Utrecht, Netherlands. ${ }^{2}$ Department of Tranzo Scientific Centre for Care and Well-being, Tilburg University, Tilburg, Netherlands. ${ }^{3}$ Pharos, Dutch Centre of Expertise on Health Disparities, Utrecht, Netherlands. ${ }^{4}$ Department of Health, Medical and Neuropsychology, Institute of Psychology, Leiden University, Leiden, Netherlands. ${ }^{5}$ Radboud university medical center, Radboud Institute for Health Sciences, Department of Primary and Community Care, Nijmegen, Netherlands. ${ }^{6}$ Faculty of Health and Social Sciences, University of South-Eastern Norway, Drammen, Norway.
Received: 3 June 2020 Accepted: 24 September 2020

Published online: 07 October 2020

\section{References}

1. Van Dulmen AM, Bensing JM. Health promoting effects of the physicianpatient encounter. Psychol Health Med. 2002;7:289-21.

2. Van Vliet LM, Epstein AS. Current state of the art and science of patientclinician communication in progressive disease: patients' need to know and need to feel known. J Clin Oncol. 2014:32:3474.

3. Sørensen K, Pelikan JM, Röthlin F, Ganahl K, Slonska Z, Doyle G, Fullam J, Kondilis Bm Agrafiotis D, Uiters E, Falcon M, Mensing M, Tchamov K, van den Broucke S, Brand H, HLS-EU Consortium. Health literacy in Europe: comparative results of the European health literacy survey (HLS-EU). Eur J Pub Health. 2015;25:1053-8.

4. Heijmans M, Brabers AEM, Rademakers J. Health literacy in Nederland. Nivel, 2018.

5. Sørensen K, Van den Broucke S, Fullam J, Doyle G, Pelikan J, Slonska Z, Brand $\mathrm{H}$. Health literacy and public health: a systematic review and integration of definitions and models. BMC Public Health. 2012;12:80.

6. Henselmans I, Heijmans M, Rademakers J, van Dulmen S. Participation of chronic patients in medical consultations: patients' perceived efficacy, barriers and interest in support. Health Expect. 2015:18:2375-88.

7. Heijmans M, Zwikker H, van der, Heide I, Rademakers J. Kennisvraag 2016: zorg op maat. Hoe kunnen we de zorg beter laten aansluiten bij mensen met lage gezondheidsvaardigheden? Utrecht: Nivel; 2016.

8. Flierman I, Nugteren IC, van Seben R, Buurman BM, Willems DL. How do hospital-based nurses and physicians identify the palliative phase in their patients and what difficulties exist? A qualitative interview study. BMC Palliat Care. 2019:18:54.

9. Arias-Casais N, Garralda E, Rhee JY, Lima L, Pons-Izquierdo JJ, Clark D, Hasselaar J, Ling J, Mosoiu D, Centeno C. EAPC atlas of palliative care in Europe. Vilvoorde: EAPC Press; 2019

10. Bélanger E, Rodríguez C, Groleau D. Shared decision-making in palliative care: a systematic mixed studies review using narrative synthesis. Pall Med. 2011;25:242-61.

11. Virdun C, Luckett T, Davidson PM, Phillips J. Dying in the hospital setting: a systematic review of quantitative studies identifying the elements of endof-life care that patients and their families rank as being most important. Pall Med. 2015:29:774-96.

12. Oosterveld M, Noordman J, Rademakers J. Kennissynthese: Samen beslissen in de spreekkamer: ervaringen en behoeften van mensen met beperkte gezondheidsvaardigheden. Utrecht: Nivel; 2019.

13. Jabbarian LJ, Zwakman M, van der Heide A, Kars MC, Janssen DJ, Van Delden JJ, Rietjens JAC, Korfage IJ. Advance care planning for patients with chronic respiratory diseases: a systematic review of preferences and practices. Thorax. 2018;73:222-30.

14. Chou WYS, Gaysynsky A, Persoskie A. Health literacy and communication in palliative care. New York: Oxford University Press; 2015.

15. Noordman J, van Vliet LM, Kaunang M, van den Muijsenbergh M, Boland G, van Dulmen S. Towards appropriate information provision for and decisionmaking with patients with limited health literacy in hospital-based palliative care in Western countries: a scoping review into available communication strategies and tools for healthcare providers. BMC Palliat Care. 2019:18:37.

16. Van Vliet LM, Francke A, Tomson S, Plum N, van der Wall E, Bensing J. When cure is no option: how explicit and hopeful can information be given? A qualitative study in breast cancer. Patient Educ Couns. 2013;90:315-22.

17. Sep MS, Van Osch M, Van Vliet LM, Smets EM, Bensing JM. The power of clinicians' affective communication: how reassurance about nonabandonment can reduce patients' physiological arousal and increase information recall in bad news consultations. An experimental study using analogue patients. Patient Educ Couns. 2014;95:45-52.

18. Van Osch M, Sep M, van Vliet LM, van Dulmen S, Bensing JM. Reducing patients' anxiety and uncertainty, and improving recall in bad news consultations. Health Psychol. 2014;33:1382

19. Dockray S, Steptoe A. Positive affect and psychobiological processes. Neurosci Biobehav Rev. 2010:35:69-75.

20. Di Blasi Z, Harkness E, Ernst E, Georgiou A, Kleijnen J. Influence of context effects on health outcomes: a systematic review. Lancet. 2001;357:757-62.

21. Van den Brink CL, Savelkoul M. Gezondheidsmonitor GGD'en, CBS en RIVM. Volksgezondheid Toekomst Verkenning, Nationaal Kompas Volksgezondheid. RIVM: Bilthoven; 2013. 
22. Aarts, M. Socioeconomic determinants of cancer risk, detection, and outcome in the Netherlands since 1990. PhD thesis. Erasmus Universiteit Rotterdam, 2012.

23. Central Bureau for Statistics definition. https:/www.cbs.nl/nl-nl/artikelen/ nieuws/2017/50/lager-opgeleiden-minder-gezond-en-tevreden/opleiding. 2017. Accessed 5 March 2020.

24. Chew LD, Bradley KA, Boyko EJ. Brief questions to identify patients with inadequate health literacy. Health. 2004;11:12.

25. Factsheet Laaggeletterdheid en beperkte gezondheidsvaardigheden. Pharos. 2018. https://www.pharos.nl/factsheets/laaggeletterdheid-enbeperkte-gezondheidsvaardigheden/ Accessed 12 May 2020.

26. Jansen J, Butow PN, Van Weert JC, van Dulmen S, Devine RJ, Heeren TJ, Bensing JM, Tattersall MH. Does age really matter? Recall of information presented to newly referred patients with cancer. J Clin Oncol. 2008;26: $5450-7$.

27. Chen $\mathrm{CH}$, Kuo SC, Tang ST. Current status of accurate prognostic awareness in advanced/terminally ill cancer patients: systematic review and metaregression analysis. Pall Med. 2017;31:406-18. https://doi.org/10.1177/ 0269216316663976.

28. De Graaf FM, Francke AL, van den Muijsenbergh ME, van der Geest S. 'Palliative care': a contradiction in terms? A qualitative study of cancer patients with a Turkish or Moroccan background, their relatives and care providers. BMC Palliat Care. 2010;9:19.

29. LeBlanc TW, Temel JS, Helft PR. "How much time do I have?": communicating prognosis in the era of exceptional responders. Am Soc Clin Oncol Educ Book. 2018:38:787-94.

30. Vermylen JH, Szmuilowicz E, Kalhan R. Palliative care in COPD: an unmet area for quality improvement. Int J Chron Obstruct Pulmon Dis. 2015;10: 1543-51.

31. Communicatie op maat gesprekken voeren. Pharos/KNMP. 2019. https:// www.pharos.nl/kennisbank/checklist-communicatie-op-maat-gesprekkenvoeren/. Accessed 12 May 2020.

32. Gillespei H, Kelly M, Duggan S, Dornan T. How do patients experience caring? Scoping review. Patient Educ Couns. 2017;100:1622-33.

33. Chu Cl, Tseng CCA. A survey of how patient-perceived empathy affects the relationship between health literacy and the understanding of information by orthopedic patients? BMC Public Health. 2013;13:155.

34. Van Vliet LM, van der Wall E, Plum NM, Bensing JM. Explicit prognostic information and reassurance about nonabandonment when entering palliative breast cancer care: findings from a scripted video-vignette study. J Clin Oncol. 2013;31:3242-9.

35. Olsman E, Duggleby W, Nekolaichuk C, Willems D, Gagnon J, Kruizinga R, Leget C. Improving communication on hope in palliative care. A qualitative study of palliative care professionals' metaphors of hope: grip, source, tune, and vision. J Pain Symptom Manag. 2014;48:831-8

36. Soundy A, Stubbs B, Freeman P, Coffee P, Roskell C. Factors influencing patients' hope in stroke and spinal cord injury: a narrative review. Int J Ther Rehabil. 2014:21:210-8.

37. Fogarty LA, Curbow BA, Wingard JR, McDonnell K, Somerfield MR. Can 40 seconds of compassion reduce patient anxiety? J Clin Oncol. 1999;17:371.

38. Rademakers J. Kennissynthese: gezondheidsvaardigheden: niet voor iedereen vanzelfsprekend. NIVEL: Utrecht; 2014

39. Van Vliet LM, Francke AL, Westendorp J, Hoffstädt H, Evers AW, van der Wall $E$, de Jong P, Peerdeman KJ, Stouthard J, van Dulmen S. The use of expectancy and empathy when communicating with patients with advanced breast Cancer; an observational study of clinician-patient consultations. Front Psychiatr. 2019;10:464.

\section{Publisher's Note}

Springer Nature remains neutral with regard to jurisdictional claims in published maps and institutional affiliations.

Ready to submit your research? Choose BMC and benefit from:

- fast, convenient online submission

- thorough peer review by experienced researchers in your field

- rapid publication on acceptance

- support for research data, including large and complex data types

- gold Open Access which fosters wider collaboration and increased citations

- maximum visibility for your research: over $100 \mathrm{M}$ website views per year

At BMC, research is always in progress.

Learn more biomedcentral.com/submissions 